by the ratio of biogas production to organic matter input : 0.20 to $0.3 \mathrm{~m}^{3} / \mathrm{kg}$ organic matter.

When considering the period of steady operation, i.e. without technical problems such as blocking of pumps or pipes, mixing difficulties, the output was improved.

Selfconsumption represented about 50 p. 100 of the energy produced and mainly corresponded to the heating of fresh manure. Selfconsumption was all the larger as manure was diluted.

According to economic calculations the return to investment length ranged from 13 to 3 years if considering valorized energy only and from 9 to 3 years when referring to available energy, i.e. potentially economizable energy. This length of return was improved when integrating the deodorization costs. On the basis of these results, it may be expected that a good preliminary study may contribute to obtaining conditions leading to a profitable investment.

VII. - FEEDING

\title{
Estimation of amino acid availability
}

\author{
J.P. LAPLACE *, Béatrice DARCY-VRILLON *, M. PICARD ** \\ Institut National de la Recherche Agronomique \\ * Laboratoire de Physiologie de la Nutrition, 78350 Jouy-en-Josas \\ ** Station de Recherches Avicoles, Nouzilly, 37380 Monnaie
}

The purpose of this report was to give guidelines for choosing an estimation method of amino acid availability to be used in practice for the formulation of diets on the basis of digestible amino acids. The definition of availability is recalled and the methods used to estimate it briefly cxamined; that based on measurements of the apparent digestibility being apparently the most fitted one. The importance of endogenous matters and the possible interest of determining a true digestibility are underlined. The error occurring in a faecal balance due to the activity of the large intestinal microflora leads to using the ileal digestibility. The different methods available in the laboratories (fistulation) are examined. The new technical solutions developed recently for practical reasons are critically analysed with the aim of surveying their advantages and detect their possible sources of errors.

The advantage of using digestible amino acid composition tables is emphasized in relation to diet formulation demands. 